\title{
A population study on rheumatoid arthritis in Lesotho, southern Africa
}

\author{
J D MOOLENBURGH,${ }^{1}$ H A VALKENBURG,${ }^{2}$ AND P B FOURIE ${ }^{3}$
}

From the ${ }^{1}$ Scott Hospital, Morija, Lesotho; the ${ }^{2}$ Department of Epidemiology, Erasmus University of Rotterdam, The Netherlands; and the ${ }^{3}$ Tuberculosis Research Institute of the South African Medical Research Council, Pretoria, Republic of South Africa.

SUMMARY Motivated by the results of a hospital study on rheumatoid arthritis (RA) in Lesotho (southern Africa) a survey of inflammatory polyarthritis (IP) and RA was undertaken in a sample of the rural population of that country. Contrary to expectations the prevalence of IP grades $2-4$ (definite disease) was low $(0.4 \%)$ and equal in both sexes, while probable and definite RA combined (American Rheumatism Association (ARA) criteria) occurred in $1.8 \%$ of both males and females. RA was slightly more severe than in other rural African Negro studies but less so when compared with the disease condition of the patients observed in the hospital study. Rheumatoid factor and particularly that directed against heterologous antigen occurred in $41 \%$ of the RA patients and in $16 \%$ of the controls. Two thirds of the definite cases and $29 \%$ of the combined probable and definite group showed radiological abnormalities.

Key word: epidemiology.

In a previous paper we described the results of a hospital study on the occurrence of rheumatoid arthritis (RA) in Lesotho, a small independent country in southern Africa. ${ }^{1}$ The number of outpatients observed with 'definite' or 'classical' RA according to the ARA criteria ${ }^{2}$ was much higher and their condition also much more serious than that of patients seen in other African hospitals. ${ }^{3-7}$ This was an interesting finding, especially as Lesotho is climatically the coldest African country because of its high altitude and its relatively low latitude. Lesotho therefore resembles temperate countries in Europe and typical tropical diseases are absent. Since data from other African population studies suggest lower prevalence rates for RA than in populations in temperate America and Europe a population study of this condition was carried out in a random sample of eight Lesotho villages. The aims were to determine whether the prevalence of RA was comparable with that observed in temperate climates and if the disease followed a more severe course than that observed in tropical African communities.

Accepted for publication 29 January 1986.

Correspondence to $\mathrm{Dr} \mathrm{H}$ A Valkenburg, Department of Epidemiology, Medical Faculty, Erasmus University, PO Box 1738, 3000 DR Rotterdam. The Netherlands.

\section{Population and methods}

The survey was linked to a point prevalence study of pulmonary tuberculosis executed by the SAMRC Tuberculosis Research Institute at Pretoria (RSA). After stratification for the four topographical zones of Lesotho eight villages were selected randomly from the 1976 census report: four from the lowlands (1500-1750 $\mathrm{m}$ above sea level), two from the foothills $(1750-2000 \mathrm{~m})$, and one each from the mountains $(2000+\mathrm{m})$ and Orange River. Valley (1000-1500 m). When the villages proved to harbour less than 400 inhabitants of all ages they were where possible grouped together with neighbouring villages according to the methods outlined by the WHO in $1958 .^{8}$ The smallest village or combination of villages contained 200 people and the largest 1779. In the weeks preceding the examination a registration clerk/motivator registered the sampling units. Each individual was given an attendance card which signified entry into the study and was to be handed over on arrival at the examination station. Every village was visited again three days after the first round of examinations for reading of the tuberculin skin test.

Respondents of 15 years and older were asked the following five questions by an experienced African 
interpreter of the Scott Hospital: (1) Do you suffer from stiffness in your joints on waking up in the morning? (2) Do you suffer from pain in your hands or feet? (3) Have you ever suffered, or are you still suffering from swelling of joints in your hands or feet? (4) Do you have deformed hands or feet? (excluding accidental injury)? (5) Do you have any deterioration in the use of your hands? The interpreters had been extensively trained to understand the meaning of the five questions, which could only be answered by 'yes' or 'no'.

When a person answered affirmatively to at least one of these questions both hands and feet were examined, and if rheumatic abnormalities were noted examination was extended to include the other joints also. In cases denying symptoms only the hands were quickly inspected. Serum specimens of all suspected individuals were examined for the presence of rheumatoid factor (RF) by the latex fixation test (LFT) and the human erythrocyte agglutination test (HEAT) as described earlier. ${ }^{10}$ The next two persons seen during the survey of the same sex and age group were taken as controls for RF. In addition, uric acid levels were determined by the automated enzymatic method. ${ }^{11}$ Radiographs of the hands were taken, where possible, of all persons aged 45 years and older and of individuals with clinically suspected RA. This was achieved by means of an Odelca camera used by the tuberculosis team, which provided $10 \times 10 \mathrm{~cm}$ pictures. Radiographs were subsequently examined twice by one of us (HAV) applying the Atlas of Standard Radiographs ${ }^{12}$ and magnifying them four times. HAV had no knowledge of either the clinical or the serological findings at the time the radiographic analysis was carried out. The Odelca arrangement did not allow for radiographs of the feet.

Classification of the respondents was achieved by application of the ARA criteria ${ }^{2}$ or the modified Rome criteria for inactive RA, ${ }^{13}$ as used in previous African surveys. ${ }^{14}{ }^{15}$ In addition, the Manchester grading for $I \mathrm{P}^{16}$ was carried out according to a five point scale: grade 0 representing no abnormalities; grade 1 doubtful changes; grade 2 definite, but mild changes; grade 3 moderate changes; and grade 4 severe disease.

\section{Results}

Of the 615 eligible men over 15 years of age, 280 $(45.5 \%)$ responded and of the 1137 women, 790 $(69.5 \%)$. Nine per cent of the mainly younger men, employed in South African mines, and less than $4 \%$ of the women were temporarily absent. For individuals above the age of $\mathbf{4 5}$ years the completion rate for women was $76 \cdot 3 \%$, while that for men was
Table 1 Sensitivity, specificity, and predictive value of each single question of the questionnaire for the 18 individuals with inflammatory polyarthritis grades $1-4$ and the four with grades 2-4

Questions*
No 2
$n \quad \%$$\frac{\text { No } 3}{n \%} \frac{\text { No } 4}{n \%} \frac{\text { No } 5}{n \%}$

\begin{tabular}{|c|c|c|c|c|c|c|c|c|}
\hline \multicolumn{9}{|l|}{ Grades 1-4 } \\
\hline Sensitivity & 15 & 83 & 7 & 39 & 6 & 33 & 6 & 33 \\
\hline Specificity & & 87 & & 92 & & 98 & & 96 \\
\hline Predictive value & & 10 & & 8 & & 21 & & 13 \\
\hline \multicolumn{9}{|l|}{ Grades 2-4 } \\
\hline Sensitivity & 4 & 100 & 1 & 25 & 2 & 50 & 1 & 25 \\
\hline Specificity & & 86 & & 92 & & 97 & & 96 \\
\hline Predictive value & & 3 & & 1 & & 7 & & 2 \\
\hline
\end{tabular}

${ }^{*}$ None of the individuals with RA or IP gave an affirmative answer 0 to question No 1.

$64 \cdot 0 \%$. The differences in response rates can be explained by the fact that men, although registered as belonging to the household, were actually absent.

One out of every five respondents was examined clinically, as $20.1 \%$ of the people answered at least one question affirmatively. The question about pain had by far the highest sensitivity, whereas the question on deformities had the highest predictive value for IP (Table 1). The questions about joint $\mathbb{D}$ swelling and usefulness of the hands were less $\overrightarrow{\vec{P}}$ valuable, and the question on morning stiffness had $\frac{\mathrm{O}}{3}$ both a sensitivity and predictive value of zero. Sensitivity, specificity, and predictive values of the different questions were essentially the same when calculated for probable and definite RA.

\section{CLINICAL ASSESSMENT}

No rheumatoid abnormalities were detected on inspection of the hands of all those who gave negative answers to all five questions. Rheumatoid $\frac{9}{9}$ nodules were not observed.

Eighteen respondents presented with grade $1-4 \stackrel{2}{2}$ IP. Two women and one man had IP grade 2 and only one, a 63 year old woman, had severe crippling arthritis grade 4 . This last individual had to 0 be visited specially at her home since she could not $\tilde{\omega}^{N}$ come to the examination centre. No radiographs could be obtained of this woman.

All the cases with IP grades 2-4 were aged $45 \frac{\Phi}{\varnothing}$ years and older and all those with grade 1 IP fell in $\stackrel{\odot}{+}$ the age category 35 years and older. Of the nine $T$ persons with grade 1 (doubtful) IP whose hands could be $x$ rayed, one had grade 2 erosive arthritis $\stackrel{\mathbb{Q}}{\mathscr{Q}}$ (EA), and of the 11 whose blood was taken, four $\stackrel{\mathbb{Q}}{\varrho}$ had a positive RF test, of whom one was the person 
Table 2 Relation between clinical assessment (IP and RA) and erosive arthritis $(E A)$ or rheumatoid factor $(R F)$

\begin{tabular}{|c|c|c|c|c|c|}
\hline \multirow[t]{2}{*}{$\begin{array}{l}\text { Clinical } \\
\text { grading }\end{array}$} & \multirow[t]{2}{*}{$\begin{array}{l}\text { Total } \\
(n)\end{array}$} & \multicolumn{2}{|c|}{$\begin{array}{l}\text { Erosive arthritis } \\
\text { (grades 2-4) }\end{array}$} & \multicolumn{2}{|c|}{$\begin{array}{l}\text { Rheumatoid factor } \\
\text { (LFT or HEAT, or } \\
\text { both) }\end{array}$} \\
\hline & & $\begin{array}{l}\text { X Ray } \\
\text { available } \\
\text { (n) }\end{array}$ & $\begin{array}{l}\text { Positive } \\
\text { (n) }\end{array}$ & $\begin{array}{l}\text { Serum } \\
\text { available } \\
\text { (n) }\end{array}$ & $\begin{array}{l}\text { Positive } \\
\text { (n) }\end{array}$ \\
\hline $\begin{array}{l}\text { IP grade } 1 \\
\text { IP grade } 2+ \\
\text { Total }\end{array}$ & $\begin{array}{r}14 \\
4 \\
18\end{array}$ & $\begin{array}{r}9 \\
3 \\
12\end{array}$ & $\begin{array}{l}1 \\
2 \\
3(25 \%)\end{array}$ & $\begin{array}{r}11 \\
4 \\
15\end{array}$ & $\begin{array}{l}4 \\
2 \\
6(40 \%)\end{array}$ \\
\hline $\begin{array}{l}\text { RA probable } \\
\text { RA definite } \\
\text { Total }\end{array}$ & $\begin{array}{r}16 \\
3 \\
19\end{array}$ & $\begin{array}{r}12 \\
2 \\
14\end{array}$ & $\begin{array}{l}2 \\
2 \\
4(29 \%)\end{array}$ & $\begin{array}{r}14 \\
3 \\
17\end{array}$ & $\begin{array}{l}5 \\
2 \\
7(41 \%)\end{array}$ \\
\hline None & 1047 & 193 & $3^{*}(1 \cdot 6 \%)$ & 45 & $7(16 \%)$ \\
\hline
\end{tabular}

*One case with septic arthritis; two with EA of distal interphalangeal joints only.

with EA. Of the four persons with grade 2-4 IP, two had a positive RF test, and two of those with grade 2 IP had grade 2 EA (Table 2).

\section{RADIOGRAPHIC ASSESSMENT}

Radiographs of the hands were taken of 216 respondents, of whom only six were under the age of 45 years. In a few villages no radiographs could be taken due to the inaccessibility of the area for the $x$ ray van.

Grade 2-4 EA was observed in three $(4.7 \%)$ of the men and in four $(2.6 \%)$ of the women whose hands were radiographed. The only case of grade 4 EA was probably due to septic arthritis, both on clinical and radiological grounds. Of the remaining six films, two showed EA of the distal interphalangeal joints only, and these persons did not have clinical signs of RA. Grade 1 (doubtful) EA was
Table 3 Relation between IP and RA

\begin{tabular}{lllll}
\hline IP grade & \multicolumn{4}{l}{ Rheumatoid arthritis } \\
\cline { 2 - 5 } & $\begin{array}{l}\text { None } \\
(n)\end{array}$ & $\begin{array}{l}\text { Probable } \\
(n)\end{array}$ & $\begin{array}{l}\text { Definite } \\
(n)\end{array}$ & $\begin{array}{l}\text { Total } \\
(n)\end{array}$ \\
\hline 0 & 0 & 5 & 0 & 5 \\
1 & 4 & 10 & 0 & 14 \\
$2+$ & 0 & 1 & 3 & 4 \\
Total & 4 & 16 & 3 & 23 \\
\hline
\end{tabular}

found in eight $(12 \cdot 5 \%)$ of the men and in $23(15 \cdot 1 \%)$ of the women. The two foothill villages showed a significantly higher prevalence of grade 1-4 EA than the two lowland villages in which radiographs were obtained $\left(\chi^{2}=9.07 ; 0.001<p<0.005\right)$.

\section{SEROLOGICAL ASSESSMENT \\ Rheumatoid factor}

Blood for the assessment of rheumatoid factor was obtained from a group of 68 respondents, 10 of whom were under the age of 45 years. There were no obvious differences in titre distributions between the 19 men and the 49 women in the group. The prevalence of a positive LFT was $12 \%$, while that of the HEAT was $21 \%$. In controls these percentages dropped to $6 \%$ and $15 \%$ respectively. All sera with a positive LFT were also positive for the HEAT. No positive results were seen in individuals under the age of 55 years, but the sample was small. The higher rate for a positive heterologous RF test was mainly due to the higher frequencies for the HEAT in the age group of 75 years and over. The highest titres for the LFT (both more than 1/5120) were found in two respondents with definite RA.

\section{Serum uric acid}

Serum uric acid values ranged between 3.4 and 7.9

Table 4 Age and sex specific prevalence of combined 'probable' and 'definite' rheumatoid arthritis

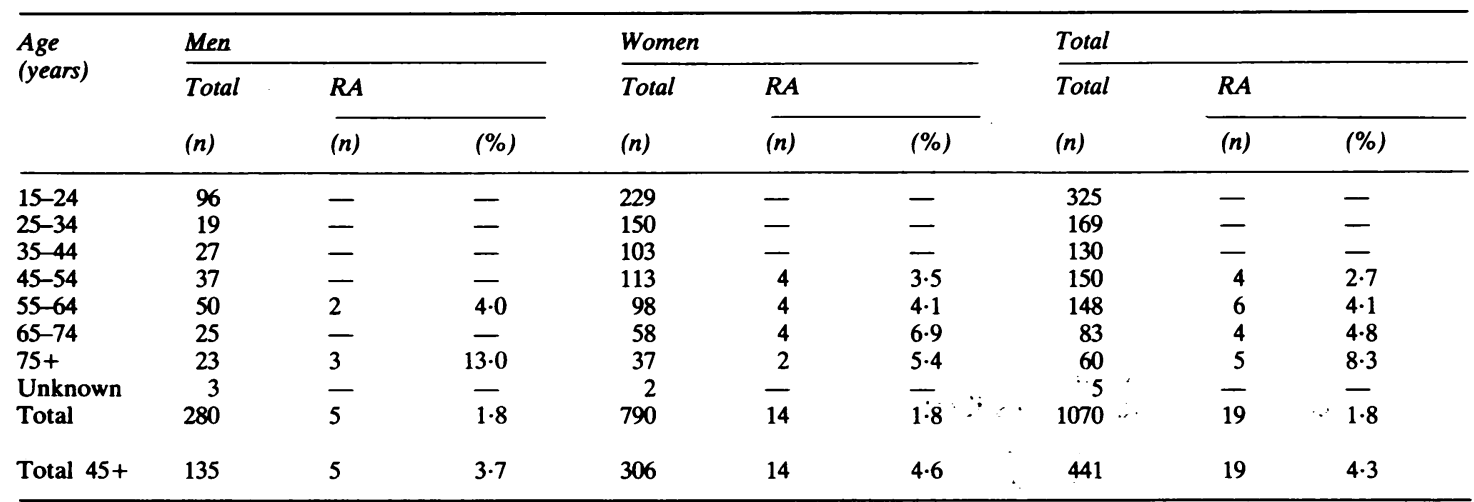


$\mathrm{mg} / \mathrm{dl}(0 \cdot 2-0.47 \mathrm{mmol} / \mathrm{l})$. There was no relation between serum uric acid values and joint pain or swelling.

EVALUATION OF COMBINED CRITERIA No case of inactive RA was encountered. There were three respondents fulfilling the criteria for the diagnosis of definite RA; all were women over the age of 55 years. This represents a prevalence of $0.38 \%$ of all females seen and of $0.28 \%(95 \%$ confidence interval $0.06-0.87 \%$ ) for both sexes combined.

Probable RA was diagnosed in 16 individuals (five men and 11 women). In two of the 12 cases in whom radiographs were obtained grade 2 EA was observed. RF was found in five of the 14 persons tested (Table 2). In 10 of the 16 individuals grade 1 IP was defined and in one grade 2 IP. On the other hand, of the 14 people with grade 1 IP, $10(71 \%)$ had probable RA (Table 3 ).

The combined prevalence for probable and definite RA was $1 \cdot 8 \%$ for all ages examined and $4.3 \%$ in persons 45 years of age and over. There was no difference in prevalence between men and women (Table 4). No case of probable or definite RA was found under the age of 45 years. Above that age a suggestive gradual increase in prevalence was observed.

\section{Discussion}

In common with other African surveys the Lesotho population study suffered from several constraints. The response rates in the younger age groups were low, but it should be realised that in the West African survey the response rate could not even be measured. ${ }^{17}$ As in other African studies the sample turned out to be small, not the least because in developing countries up to $50 \%$ of the population consists of children. The deficit of younger able men biases the sample towards less healthy, older men, which might explain the surprisingly similar prevalence of IP and probable+definite RA in the two sexes.

As it was realised that it would be impossible physically to examine all respondents a questionnaire was applied in order to select individuals deserving clinical assessment. Futhermore, it was assumed that simple inspection of the hands of people lacking rheumatic complaints would ensure that the number of cases of RA missed would be reduced to a minimum. Despite the eagerness of the tuberculosis team to obtain radiographs, bad weather conditions and inaccessible roads frequently prevented use of the Odelca system. Blood sampling fortunately did not constitute a major

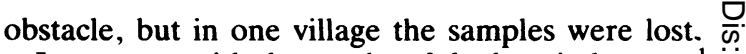

In contrast with the results of the hospital survey ${ }^{1} \stackrel{\Rightarrow}{\Rightarrow}$ the prevalence of clinical IP was low, and in the $\stackrel{\vec{D}}{+}$ majority of suspected individuals the condition was clinically very mild. This corresponds to the findings of the surveys among the rural Tswanas in South Africa, ${ }^{15}$ and the Xhosas of the Transkei bordering $\stackrel{\varnothing}{\varnothing}$ on Lesotho. ${ }^{18}$ Both these populations are genetically के closely linked to the Sothos but live in different $\overrightarrow{0}$ climatological conditions and presumably suffer from other infectious diseases. The same low prevalence and mild condition of RA were seen in the hot, humid tropical climate of Liberia and Nigeria, ${ }^{17}$ where parasitic infections prevail.

The only exception to this pattern was observed in the mixed urban population of Soweto, ${ }^{14}$ where the 8 prevalence of RA was as high as in Europe and where a number of patients with severe RA, 을 particularly females, were encountered. Although $\rightarrow$ the prevalence rate of $3.3 \%$ in Soweto for probable and definite RA combined differed significantly from the corresponding figure of $0.87 \%$ among the $\stackrel{\omega}{\rightarrow}$ rural Tswanas, it did not differ from the $1.8 \% \overrightarrow{0}$ combined prevalence in Lesotho, from the $2.2 \% \%$ found in the Transkei, and from the $2.3 \%$ observed in West Africa. These figures are likely to be real since in each of these surveys (Lesotho excepted) a physician from a previous survey took part. ${ }^{14} 151718$

On the other hand, it has been the impression of one of us (HAV) who participated both in the West African survey and in a number of South African surveys that many probable cases in Africa do not represent genuine RA. This was confirmed in the survey in Lesotho, e.g., four persons were found to be suffering from bilateral soft tissue swelling of the ankles and might even have been classified as 'definite' RA in the event of positive radiological or 3 serological findings even though they did not receive any clinical grading at all on examination.

As in other African surveys seropositivity for RF 의 was considerably higher than in Europe. Tropical $>$ parasitic infections being absent in Lesotho cannot $\frac{0}{3}$ be held responsible for this phenomenon. Other prevailing infections such as tuberculosis or venereal $\sigma$ disease have to be considered, but the hospital study $N$ suggested that these are not important factors. ${ }^{1}$

In the population study 62 persons showed abnormalities on chest $x$ ray: IP grade 1 or more was 0 diagnosed five times and probable RA six times in $\overparen{\varnothing}$ this group. In 30 cases the chest $x$ ray abnormalities $\stackrel{?}{+}$ were considered to be tuberculous in origin; four of $\underline{T}$ the 19 persons tested for RF in this group were positive. Although there is some suggestion that tuberculosis infection might be related to a positive $\stackrel{\AA}{\AA}$ RF factor test, the figures are small. 
A remarkable feature of this study is the much higher rate of a positive HEAT as compared with the LFT. This contrasts with all other African surveys and especially with that conducted in the Transkei. With the exception of the Transkei the results from the various surveys are comparable as the tests were either done by the same laboratory or the test systems had been standardised.

There was a fair correlation between observed radiological abnormalities (EA) in the hands and rheumatoid disease as classified by the ARA criteria or Manchester grading (Table 2). This pattern is similar to that observed in studies in populations in temperate regions. The same may be said of the percentage false positive EA.

It is not easy to explain the incongruency between the results of the hospital study and the population survey in Lesotho. One possible explanation is selection bias towards the hospital of more severely ill RA patients because of the hospital's reputation for dealing with rheumatic conditions. This is considered to be unlikely, however. Another explanation could be that in Lesotho better transport facilities exist than elsewhere in Africa, enabling easier access to the hospital. Furthermore, the low prevalence rate in the attending people could be due to a selective hiding of crippled persons among the non-respondents ${ }^{19}$ or the result of an increased mortality ${ }^{20}$ because of rapidly deteriorating RA, as was suggested by the observations in the clinic patients. The better medical situation in Soweto could then have led to a longer survival of severely affected patients. Since it has been recently suggested that HLA-DR4 is more related to a severe course of the disease than to its causation, ${ }^{21}$ it would be interesting to know the profile of this antigen in the different African ethnic groups.

An attempt will be made in the future to construct a hypothesis for the varying pattern of rheumatoid disease in Africans in relation to the possible role of environmental (trauma, climate, infections, urbanisation) and genetic factors. Furthermore, the value of the different sets of criteria for rheumatoid abnormalities will be analysed when these are applied under primitive survey conditions and recommendations will be formulated for relatively efficient and effective surveys on rheumatic conditions in developing countries.

We thank Drs $\mathrm{H}$ Logan (tuberculosis officer, Lesotho) and $\mathrm{H}$ Kleeberg (director, TBRI) for allowing us to join the tuberculosis survey and make use of the radiological facilities, among others: Dr F Klein for the rheumatoid factor determination and together with Drs J Seggie and J P Vandenbroucke for critically reading the manuscript.

\section{References}

1 Moolenburgh J D, Moore S, Valkenburg H A, Erasmus M G. Rheumatoid arthritis in Lesotho. Ann Rheum Dis 1984; 43: 40-3.

2 Ropes M W, Bennett G A, Cobb S, Jacox R, Jessar R. The revised ARA critera for RA. Ann Rheum Dis 1959; 18: 49-53.

3 Hall L. Polyarthritis in Kenya. East Afr Med J 1966; 43: 161-70.

4 Gelfland M. Medical arthritis in African practice. Cent Afr J Med 1969; 15: 131-5.

5 Greenwood B M. Polyarthritis in Western Nigeria. I. Rheumatoid arthritis. Ann Rheum Dis 1969; 28: 488-96.

6 Kanyerezi B R, Baddeley H, Kisumba D. Rheumatoid arthritis in Ugandan Africans. Ann Rheum Dis 1970; 29: 617-21.

7 Bagg L R, Hansen D P, Lewis C, Houba V. Rheumatoid arthritis in Kenya. I. Clinical observations. Ann Rheum Dis 1979; 38: 23-5.

8 Tuberculosis Research Office Technical Guide of the WHO. 1958: No 1.

9 Valkenburg H A. The latex fixation test (LFT). In: Kellgren J H, Jeffrey M R, Ball J, eds. The epidemiology of chronic rheumatism. Oxford: Blackwell, 1963; i: 337-9.

10 Valkenburg $\mathrm{H} \mathrm{A}$. The human erythrocyte agglutination test (HEAT). In: Kellgren J H, Jeffrey M R, Ball J, eds. The epidemiology of chronic rheumatism. Oxford: Blackwell, 1963, i: $330-3$.

11 Gochman N, Schmitz J M. Automated determination of uric acid, with the use of uricase-peroxidase system. Clin Chem 1971; 17: 1154-9.

12 Atlas of standard radiographs of arthritis. In: Kellgren $\mathrm{J} \mathrm{H}$, Jeffrey M R, Ball J, eds. The epidemiology of chronic rheumatism. Oxford: Blackwell, 1963: 2.

13 Kellgren J H. Diagnostic criteria for population studies. Bull Rheum Dis 1962; 13: 291-2.

14 Solomon L, Robin G, Valkenburg H A. Rheumatoid arthritis in an urban South African Negro population. Ann Rheum Dis 1975; 34: 128-35.

15 Beighton P, Solomon L, Valkenburg H A. Rheumatoid arthritis in a rural South African Negro population. Ann Rheum Dis 1975; 34: 136-41.

16 Lawrence J S. Prevalence of rheumatoid arthritis. Ann Rheum Dis 1961; 20: 11-7.

17 Muller A S. Population studies on the prevalence of rheumatic diseases in Liberia and Nigeria. Leiden, 1970. (MD thesis.)

18 Meyers O L, Daynes G, Beighton P. Rheumatoid arthritis in a tribal rural Xhosa population in the Transkei, southern Africa. Ann Rheum Dis 1977; 36: 62-5.

19 Schmidt J E. A survey of the physically handicapped in Lesotho. Report funded by the Overseas Development Ministry 1976: 25-7.

20 Lawrence J S. Rheumatism in populations. London: Heinemann, 1977: 222.

21 De Jongh B M, Van Romunde L K J, Valkenburg H A, De Lange G G, Van Rood J J. Epidemiological study of HLA and GM in rheumatoid arthritis and related symptoms in an open Dutch population. Ann Rheum Dis 1984; 43: 615-9. 